\title{
CATÓLICOS, FIDELIDADE CONJUGAL E AIDS: ENTRE A CRUZ DA DOUTRINA MORAL E AS ESPADAS DO COTIDIANO SEXUAL DOS ADEPTOS
}

\author{
Luis Felipe Rios \\ UFPE (Brasil-PE) \\ Francisca Luciana de Aquino \\ UFPE (Brasil-PE) \\ Miguel Muñoz-Laboy \\ Columbia University (NY-USA) \\ Cinthia Oliveira \\ UFPE (Brasil-PE) \\ Richard Parker \\ Columbia University (NY-USA)
}

Resumo: Neste artigo discutimos a visão da Igreja Católica sobre sexualidade na interface com a epidemia do HIV/AIDS. Nossa reflexão está embasada em pesquisa etnográfica que envolveu dois meses de observação participante do cotidiano de católicos de um bairro popular da Região Metropolitana do Recife, além de contar com entrevistas a onze dos leigos engajados nos serviços religiosos da igreja do bairro e a oito sacerdotes que realizam seus trabalhos religiosos em outras localidades. Nelas abordamos diferentes temáticas relacionadas ao enfrentamento da epidemia da AIDS. Nesse contexto, conjugalidade e fidelidade se afiguram como importantes analisadores de como aqueles lidam com a epidemia, em uma variedade de re-descrições práticas e de re-interpretações conceptuais das assertivas do discurso moral religioso - ainda que, muitos impasses permaneçam em aberto em termos das prerrogativas da Igreja e seus possíveis rebatimentos na saúde sexual dos adeptos.

Palavras-chave: Igreja Católica, Sexualidade, AIDS, Católicos

Abstract : In this article we discuss the vision of the Catholic Church about sexuality at the interface with the epidemic of HIV / AIDS. Our ideas are based on ethnographic research that involved two months of participatory observation of the daily life of Catholics in a popular neighborhood of the metropolitan area of Recife, in addition to relying on interviews with eleven of the amateur people engaged in the religious services of the church's neighborhood and eight priests who perform their religious work in other locations. In them we approach different issues related to facing the AIDS 
epidemic. In this context, marriage and loyalty seem to be important analyzers as to how they deal with the epidemic, in a variety of practical re-descriptions and conceptual re-interpretations of the assertions of moral religious speech - even though, many impasses remain open in terms of the prerogatives of the Church and its possible rebut on sexual health of adepts.

Keywords: Catholic Church, sexuality, AIDS, Catholics

\section{APRESENTAÇÃO}

Neste ensaio discutimos a visão da Igreja Católica sobre sexualidade na interface com a epidemia do HIV/AIDS. ${ }^{1}$ Nossa reflexão está embasada em pesquisa etnográfica que envolveu dois meses de observação participante do cotidiano de católicos de uma paróquia de um bairro popular da Região Metropolitana do Recife. Além de contar com registros em diário de campo dos eventos presenciados e de conversas informais com fiéis católicos residentes no bairro, entrevistamos onze dos leigos engajados nos serviços religiosos da igreja do bairro. Também realizamos entrevistas com oito sacerdotes que realizam seus serviços religiosos em outras localidades. Nas entrevistas com sacerdotes e leigos abordamos diferentes temáticas relacionadas ao enfrentamento da epidemia da AIDS.

Focando nas questões relacionadas à prevenção do HIV, ao longo do texto analisamos vivências e relatos de sacerdotes e leigos quando precisam aplicar as diretrizes do Vaticano em relação ao preconizado no que se refere à epidemia e se deparam com a realidade concreta dos rebanhos católicos recifenses. Nesse contexto, conjugalidade e fidelidade se afiguram como importantes analisadores de como aqueles lidam com a epidemia, onde é possível identificar uma série de re-descrições práticas e de re-interpretações conceptuais das assertivas do discurso moral religioso.

Organizamos o texto de modo que inicialmente buscamos apresentar o contexto mais amplo em que os dados e as análises foram constituídos, enfocando como o Vaticano e a Arquidiocese de Olinda e Recife se posicionam a respeito da AIDS.

\footnotetext{
1 Os dados coletados para a elaboração do trabalho resultam da pesquisa Respostas Religiosas ao HIV/AIDS no Brasil (Projeto financiado pelo U.S. National Institute of Child Health and Human Development, 1 R01 HD05118-01. Principal Investigador: Dr. Richard Parker - Columbia University). O estudo, de abrangência nacional, é realizado em quatro sítios específicos, nas seguintes instituições e com os respectivos coordenadores: Rio de Janeiro (Associação Brasileira Interdisciplinar de AIDS/ABIA - Dr. Veriano Terto Jr.); São Paulo (Universidade de São Paulo/USP - Dra. Vera Paiva); Porto Alegre (Universidade Federal do Rio Grande do Sul/UFRGS - Dr. Fernando Seffner) e Recife (Universidade Federal de Pernambuco/ UFPE - Dr. Luís Felipe Rios). Informações adicionais sobre o projeto podem ser obtidas pelo e-mail religiao@ abiaids.org.br ou através do site www.abiaids.org.br.
} 
Melhor localizada a problemática a qual se dirige as reflexões deste ensaio, passamos ao cotidiano dos fieis, apresentando a comunidade investigada em sua catolicidade e no modo como o sexual lá se atualiza. Sobre isto traremos para análise e discussão alguns fragmentos do cotidiano sexual dos seus integrantes católicos, na perspectiva de discutir os desafios que estas vivências colocam para o ideal católico de uma prevenção de AIDS baseada na postergação da iniciação sexual para a ocasião do matrimônio e na fidelidade conjugal.

Finalmente, e com base nesta primeira análise dos dados recolhidos entre os católicos da Região Metropolitana do Recife - ressaltemos, uma análise de cunho mais descritivo - apontamos hipóteses e questões a serem aprofundadas no que concerne a tarefa de compreender o que tem sido, ao longo destes vinte e poucos anos de epidemia do HIV/IDS no Brasil, por um lado a resposta institucional católica e por outro a dos católicos na lida do dia-a-dia.

\section{O BRASIL CATÓLICO E A EPIDEMIA DE AIDS: O CONTEXTO DA PESQUISA EM RECIFE}

Em maio de 2007 o Brasil - cantado aos quatro ventos como o maior país católico da atualidade - recebeu a visita do Sumo Pontífice da Igreja Romana, o Papa Bento XVI. Durante algumas semanas, no país, era só do que se falava. Claro que as questões sexuais, tão caras à Igreja quanto é à Saúde Pública, tomaram conta da mídia. Ao lado do posicionamento do Papa sobre as células troncos ${ }^{2}$ - assunto de ponta no norte e no sul do mundo -, aborto e AIDS figuraram como temas polêmicos que emergiram em debates acalorados envolvendo diferentes setores da sociedade brasileira - religiosos das diferentes denominações, políticos, cientistas, sociedade civil organizada, entre outros ${ }^{3}$.

Enquanto o calor da discussão ganhava a cena, nossa equipe de pesquisa, preocupada em compreender o modo como as diferentes tradições religiosas vêm respondendo à epidemia da AIDS no Recife, continuava com a difícil tarefa de arregimentar lideres religiosos católicos que aceitassem conceder entrevistas sobre o tema. Voltando no tempo, sublinhemos que ao longo de 2005 e 2006, se as entrevistas

\footnotetext{
2 Tema que ainda que não direta, ou explicitamente, se relacione ao campo da sexualidade, em diversos momentos o tangencia, uma vez que envolve questões relativas ao campo da reprodução (biológica e social).

Para um resgate sobre as discussões que emergiram com a passagem do Papa Bento no Brasil, cf. o dossiê "Em torno da visita do Papa ao Brasil", realizado pelo "Observatório de Sexualidade e Política": http://www.sxpolitics.org/mambo452/index.php?option=com_content\&task=view\&id= 83\&Itemid=111.
} 
entre pastores evangélicos e pais e mães de santo se multiplicavam a cada dia; por um bom tempo, avançar com o trabalho de campo entre os católicos foi a nossa maior dificuldade. Recorrentemente as entrevistas agendadas com freis e padres eram desmarcadas - quando estes não se recusavam de pronto em concedê-las, ao saber do que se tratava. Destacando que até hoje não conseguimos identificar, contatar e entrevistar o responsável pela Pastoral de DST/AIDS ${ }^{4}$ no Recife (se é que ela existe! ${ }^{5}$ ), nem sequer entrevistar, apesar dos muitos contatos feitos, o responsável pela Pastoral da Saúde.

\section{O arcebispo e a (prevenção da) aids}

Ainda na linha de compreender a dificuldade de obter a fala dos sacerdotes, e também na perspectiva de proporcionar ao leitor um rápido panorama do contexto mais amplo, histórico e sócio-político local, no qual a pesquisa se deu - o que possibilitará, inclusive, melhor matizar, a nível local, a polêmica acima apontada - vale discorrer, ainda que brevemente, sobre a ultima mudança de arcebispos na Arquidiocese de Olinda e Recife, e o seu impacto no trabalho social da Igreja.

Até 1985 conduzia a Igreja nas cidades de Olinda e Recife D. Helder Câmara (falecido em agosto de 1999), um dos mais importantes líderes nordestinos da perspectiva de catolicismo engajada com os problemas do mundo social. Em conversa pessoal com integrantes do Centro Dom Helder Câmara de Estudos e Ação Social CENDHEC $^{6}$ foi mencionado que com a aposentadoria do Arcebispo (que homenageiam no nome) e seu afastamento da Arquidiocese, muitas pessoas, que contribuíam no trabalho por ele liderado e/ou apoiado, deixaram as diversas pastorais existentes e fundaram ONGs para continuarem desenvolvendo trabalhos na perspectiva que vinham tomando. Justificam afirmando que o arcebispo que se seguiu, e que permanece no poder até hoje, Dom Frei José Cardoso Sobrinho, era/é de uma perspectiva extremamente conservadora, o que inviabilizava a continuidade das ações.

\footnotetext{
4 Para um resgate histórico sobre a Pastoral de DST/AIDS, cf. Seffner et ali (no prelo).

Comparando os quatro sítios de investigação desta pesquisa e comentando a invisibilidade da Pastoral de DST/AIDS no sítio do Recife, Seffner et. ali (no prelo: 4) aponta que:

Embora um órgão oficial da CNBB, isso não significa que o trabalho da Pastoral de DST/Aids encontre unanimidade entre os bispos, nem que ela seja bem vinda em toda diocese ou paróquia. Desse modo, as negociações conduzidas em cada local no momento de implantação da Pastoral podem revelar tensões entre diferentes posições no seio da Igreja Católica acerca da aids, bem como nos auxiliam a compreender qual o espaço de poder político de que dispõem as pastorais, e a Pastoral de DST/Aids em particular, na estrutura geral de ação da igreja católica no Brasil.

adolescentes.
} 
No que se refere às questões de HIV/AIDS e sexualidade, vale trazer aqui um dos pronunciamentos de Dom José, datado de julho de 2006, sobre o uso do preservativo como "mal menor" - interpretação dos mandamentos utilizada pelos católicos que, contrariando as diretrizes da Igreja, se colocam favoráveis ao uso do preservativo como forma de prevenção da AIDS. Seus esforços no artigo são o de apontar para, conforme ele, os sofismas encontrados na argumentação de que frente ao mal maior da morte se justifica o mal menor do uso do preservativo, permitindo-se (e incentivando-se) com isso a fornicação e aberrações sexuais (sic.). Deixando a referência eletrônica ${ }^{7}$ para que o leitor possa acessar o documento na íntegra, e chegar as suas próprias análise e conclusões, trazemos abaixo, como ilustração, as palavras finais do referido texto:

Alguns renitentes insistem, observando que os citados textos papais se referem ao ato
conjugal e não à fornicação ou outros pecados sexuais. Aqui também há sofismas. Se a
teoria do mal menor não justifica o uso de preservativos nem mesmo entre cônjuges
legítimos, com muito maior razão (a fortiori) a mesma teoria deve ser excluída de atos
que são sempre intrinsecamente maus, como a fornicação e outras aberrações, as quais,
conforme a Bíblia, excluem do Reino de Deus (cf 1 Cor $6,9-10 ;$ Gal 5, 19-21).
Se o supracitado silogismo fosse teoricamente válido e aceitável, dever-se-ia, como
dedução lógica, aprovar e aplaudir essa campanha indecorosa e deletéria em favor do
uso de preservativos, promovida pelo próprio governo e cuja consequiência prática
haverá de ser uma maior decadência moral na sociedade.
Este pronunciamento pode trazer indicações sobre o porquê das nossas dificuldades na inserção no campo católico. Com um líder religioso ultra-conservador à frente da arquidiocese, é de se entender as reticências dos padres à concessão de entrevistas gravadas sobre um dos assuntos mais polêmicos, no que se refere ao tratamento dado pela Igreja. Também é possível começar a entender o porquê da ausência de instituições e trabalhos em AIDS explicitamente vinculados à Igreja em Recife.

Ainda neste sentido, as notas do diário de campo de uma das pesquisadoras do projeto, referente à primeira entrevista realizada, são reveladoras da tensão que queremos abordar neste texto. Após se desligar o gravador, o diálogo recomeçou:

Comentei com ele, antes de me despedir, da dificuldade em entrevistar membros da Igreja Católica. Ele avaliou como sendo natural, pois cada estado vê a temática da AIDS sob um olhar diferente. Esclarece que se a pesquisa fosse em uma outra capital nordestina (onde realizou um trabalho anterior, inclusive mais diretamente envolvendo a questão da AIDS), a postura da Diocese seria outra. Assevera que essa reação dos padres aqui em Recife está ligada diretamente à forma como o bispo se posiciona diante destas mesmas questões. (Diário de Campo - Cinthia Oliveira, Recife/2006)

7 http://www.arquidioceseolindarecife.org.br/palavrajul.htm 
Por que, se por um lado, a posição oficial do Vaticano sobre a camisinha como forma de prevenção ao HIV é clara - uma impropriedade moral -, a dos sacerdotes e lideranças leigas, como recuperamos abaixo, nem sempre com ela se afina. Falar sobre AIDS para uma equipe de pesquisa, que, se sabe, irá registrar, refletir e se posicionar sobre o dito, envolve complexidades de diferentes âmbitos, que nem sempre os sacerdotes estão a fim de enfrentar.

Aos poucos, entretanto, e não obstante as dificuldades iniciais, conseguimos avançar no trabalho. No total entrevistamos oito sacerdotes, incluindo uma freira, que realizam seus serviços religiosos em diferentes localidades da Região Metropolitana do Recife. Ao longo das entrevistas foi cada vez mais claro para nossa equipe de pesquisa o quanto a questão das práticas sexuais fora do casamento (antes, durante e/ou depois deste) e o uso do preservativo enquanto estratégia de prevenção se constituía, como já aludimos, em incômodo ou tensão, no se posicionar sobre o que fazer quando a epidemia se espelhava entre os seus rebanhos.

A alegoria que nos ocorria, quando passávamos por muitos dos depoimentos obtidos, é a de que os sacerdotes se achavam, de certo modo, entre a cruz (diretrizes do Vaticano) e as espadas (a realidade concreta). Tensão que se expressa com maior força nos níveis intermediários da hierarquia (padres e freis) e vai, de certo modo, perdendo força discursiva na medida em que passamos para as lideranças leigas e, sobretudo, quando chegamos aos fiéis no cotidiano. Sigamos, então, por esse caminho...

\section{Atenção e prevenção: dois pesos e duas medidas}

Assim, quando as entrevistas com os sacerdotes começaram a se realizar, foi ficando claro que o "não falar" dos católicos no primeiro ano de trabalho de campo, não significava a ausência de participação de leigos e sacerdotes desta fé no enfrentamento da epidemia em Recife. Até mesmo por que, como dizia um de nossos entrevistados da tradição evangélica, nos últimos anos a AIDS bate à porta das igrejas; não há como se omitir a respeito ${ }^{8}$. Na mesma linha comenta Padre Marcos, um de nossos primeiros entrevistados, quando questionado sobre as pessoas vivendo com o HIV e o recorrer deles à Igreja:

Primeiro, uma das pastorais importantíssimas da paróquia é a Pastoral da Saúde. Ela lida, concretamente, acompanhando pessoas doentes nos hospitais e em suas casas. Então, a gente encontra, não somente na Pastoral da Saúde, mas também, por exemplo, na Pastoral da Criança, na Pastoral da Família, pessoas, ou que estão infectadas pelo

$8 \quad$ O que não signifique que a qualidade da resposta seja a mesma para todos 
vírus da AIDS, ou são familiares de alguém que tem AIDS; ou seu parceiro sexual, seu marido, seu filho; ou alguém da família, ou algum amigo tem AIDS. Então, o primeiro encontro é esse: com o doente. Normalmente, por ser um cuidado com as pessoas que estão doentes e por várias doenças decorrentes do vírus - ou melhor do enfraquecimento do sistema imunológico. Outro aspecto seriam aquelas pessoas que vêm em busca do milagre (...), concretamente em vista da AIDS. (Padre Marcos)

Do mesmo modo, quando entrevistávamos atores de outras religiões, os católicos eram citados como atuantes neste campo. Na fala do representante de uma importante ONG-AIDS de fundo cristão no Recife, por exemplo, encontramos referência a católicos na sua fundação - lembremos, no entanto, que esta surge como uma Casa de Acolhimento, uma instituição de atenção, mais afeita com o trabalho católico de assistência aos enfermos.

Assim, no relato dos diferentes entrevistados católicos, quando chamados a falar sobre AIDS de forma genérica, a prerrogativa do acolhimento se sobressaia ao modo como a pessoa contraiu o vírus (ainda que sempre mencionados), via a noção de misericórdia pela condição pecadora humana, como assinala outro dos padres entrevistados:

Então a igreja, ela se encontra diante da AIDS. Na realidade da pessoa que necessita de tratamento, da pessoa que necessita de carinho, da pessoa que necessita ser acolhida e não excluída. Então, quando se fala em AIDS, hoje, na igreja, a igreja fala claramente, enquanto sua, a referencia com aquele que necessita de ajuda, né?! Então, é a pessoa que foi infectada; e a gente não entra aí no mérito de o que foi que aconteceu. (...) Então diante, a igreja se coloca, diante de uma pessoa infectada, que necessita ser vista a partir da misericórdia, a partir daquele cuidado que Deus quer que nós tenhamos para qualquer pessoa. Uma pessoa debilitada e alguém que tenha a ver com o dado da fé, com a religião. (Padre Marcelo)

Assim, se os diferentes sacerdotes entrevistados falaram com facilidade da AIDS

via o acolhimento, o incômodo começava quando tinham que se posicionar a respeito das prerrogativas morais da Igreja sobre sexualidade, na interface com os métodos de prevenção - em outras palavras: camisinha versus abstinência/fidelidade.

De outro modo, se o trabalho da Igreja no tocante ao acolhimento aos enfermos de AIDS é, sem contestações, de importante contribuição para o enfrentamento da epidemia (no olhar dos de dentro e dos de fora da Igreja), o mesmo não se pode dizer no que se refere à prevenção. Vozes dissonantes, fora e dentro do catolicismo, avaliam a posição do Vaticano sobre a camisinha. Sobre este ponto a Igreja está em oposição frontal com o discurso e a prática oficial do governo brasileiro sobre a questão, atualizado em projetos e campanhas focadas na divulgação do preservativo enquanto única forma de se proteger da infecção pelo vírus (cf. Seffner et ali, 2007; Parker, 2003 e Parker et ali, 2005). 
Nesta linha, e analisando as falas de nossos entrevistados do Recife, podemos dizer que as posições dos sacerdotes entrevistados a respeito da camisinha parecem difíceis de serem expressas. É de se ressaltar que pronunciar-se a partir do discurso oficial da Igreja é estar falando de uma prática que, ao ser condenada (uso do preservativo), pode contribuir para expor pessoas ao risco de infecção pelo HIV, nos moldes como pensa o discurso médico vigente - em última instância é está se posicionando sobre questões que remetem à morte ou à vida. A título de exemplo, sigamos de perto o relato do Padre Julião e a sua dificuldade de expressar uma posição (ou avaliação) da postura da Igreja sobre a camisinha:

[Quais as questões que surgiram na religião do senhor em função do aparecimento da AIDS? Que o senhor poderia marcar pra gente.] Não... A igreja católica ela ficou mais, mais reservada, já pecou muito, ao longo dos tempos; e hoje é muito reservada. O que a igreja, ela tem que acolher, né? (...) Uma condenação a esse grupo de pessoas, não existe. Se bem que outras denominações condenam, né? Que é coisa do demônio, que é castigo de Deus. Isso aí é outras denominações, a igreja católica não. Ela não. Ela condena esses sexos desregrados... (...) (Padre Julião)

Como outros sacerdotes, questionado genericamente sobre AIDS e catolicismo, Padre Julião re-afirma a posição da Igreja em acolher os enfermos, inscrita nas noções de misericórdia e caridade. Antes, porém, no preâmbulo da sua resposta, aponta para uma posição mais reservada da Igreja frente à AIDS, justificando-a pelos muitos pecados desta instituição ao longo da sua história. O interdiscurso que é trazido aqui pode ser entendido como os diversos momentos em que a Igreja, ou esteve do lado de instâncias opressoras de categorias e povos, ou deixou de se posicionar contra estas (por exemplo: escravismo).

De outro modo, Padre Julião, ao colocar na frente do acolhimento, caridade e misericórdia, o lado sombrio e pecador da Igreja, parece apontar para algo que não anda bem (ou bem resolvido para ele mesmo) no que se refere ao tratamento dado pela Igreja à AIDS. Posição que ele prefere qualificar como reservada, mas que, na verdade não é tão reservada assim. Basta lembrar que (como Padre Julião mesmo irá apontar no trecho de sua entrevista que traremos a seguir), dentre outras possibilidades de fazer prevalecer sua opinião, está o constante acesso às mídias para tornar público, des-reservadamente, o que pensa a respeito da camisinha. Como tem apontado alguns críticos, essa atuação do Vaticano acaba significando uma volta ao supracitado lado sombrio da Igreja, uma vez que auxilia a colocar/deixar em situação de risco de infecção pelo HIV milhões de pessoas no mundo. 
Sigamos no relato do Padre, no momento em que ele é instado a falar claramente sobre prevenção:

[Dentro da sua religião, o que o senhor acha que facilitou a resposta para epidemia de AIDS, para ajudar na epidemia de AIDS, para evitar a epidemia?] A Igreja fala muito na conscientização, conscientizar as pessoas. Por isso que tem os grupos, grupos de jovens, né? Os casais - não é? (...) Encontros dos Casais com Cristo, ECC, encontro matrimonial... Eh, pastoral familiar, pastoral social, todas elas falam, não é? E a mídia tem usado muito, também tem feito muita propaganda. Porque na medida, em que a Igreja Católica é contra o uso do preservativo, digamos a camisinha - que vai chegar aqui até nessa época de carnaval - tem sempre alguém falando a favor, e alguém falando contra. Esse alguém falando contra sempre será um bispo - né? - falando contra o uso do preservativo, de preservação, né? E então, isso também ajuda na conscientização. Mas porque que é contra? Porque que é contra o uso do preservativo? Será que é contra por ser contra? Não, a Igreja vê como o cunho do imoral, no evangelho de Jesus, da Bíblia. Ela defende isso, mais por isso. (Padre Julião)

Neste trecho da interlocução ele é explicitamente chamado a declarar a posição

do catolicismo no que se refere à prevenção. Afirma a ação realizada em diferentes instâncias da Igreja, onde questões sexuais são tratadas, como do âmbito da proteção contra o vírus, as quais ele qualifica como "conscientização" - ainda que soe mais como um processo de heteronomização dos indivíduos, de torná-los afeitos à moral da Igreja. Só então ele parte para, ao mesmo tempo, criticar a postura do governo brasileiro em pensar a prevenção via a camisinha, e apresentar o discurso da Igreja na mídia como aquele que provoca a tensão capaz de ajudar na "conscientização" - e aqui, tendemos a concordar com ele: a pluralização de posições como capaz de possibilitar consciência, entendida enquanto a autonomização do sujeito frente às diferentes posições disponíveis no campo (a da Igreja, a do Estado etc. $)^{9}$.

Finalmente, sinaliza que o discurso do Vaticano sobre a camisinha tem uma lógica que precisa ser considerada. $\mathrm{O}$ que aparece na fala dele é que a sexualidade é para um catolicismo uma questão moral (portanto cultural - formadora das pessoas), e isso não pode ser apagado (pelo menos entre/para os católicos). O não dito é que a sexualidade se constitui em um impulso da "carne" que deve ser controlado e colocado a serviço de Deus, sob a égide da reprodução, de modo que a "alma" se espiritualize e encontre, na morte, a salvação (cf. Foucault, 1993a; Áries, 1995).

[Dentro da religião católica, o que o senhor considera que tenha sido obstáculo pra se construir uma respostas para evitar a epidemia da AIDS?] Não... A resposta tem sido, eh, a conscientização dos seus fieis, dos seus grupos, não é? Reunião, pastoral familiar, pastoral carcerária, pastoral da mulher. Quando se fala da pastoral da mulher, vale também da mulher prostituída, tem esse trabalho da mulher prostituída, hoje tem (...) $\mathbf{O}$

\footnotetext{
9 Sobre autonomia e heteronomia, cf. Enriquez (2001), para uma interessante noção de concientização, cf. Freire (1989). Vide também Paiva (1999) para uma discussão da conscientização como um processo de autonomização dos sujeitos, no âmbito da resposta ao HIV/AIDS entre adolescentes.
} 
grande obstáculo que a Igreja mantêm é o uso do preservativo. É até um paradoxo dizer uma coisa dessa, né? O governo, como o Ministério da Saúde, vê como uma preservação, né? O uso de preservativo, eh, preserva a saúde, evita a contaminação. Já a Igreja diz que isso vai perdurar, vai perdurar por muito tempo e só vai facilitar e vai ajudar a indústria farmacêutica, na produção de muitos, e muito e muitos, de milhas e milhares de camisinhas. Então a Igreja vê, que essa aspecto, como eu já falei, moral, cristã, não, he... Que ela tem uma visão, por mais arcaica que possa parecer, mas é a visão da Bíblia, que é o uso do sexo dentro do matrimonio. E para quê? Para a procriação, gerar filhos, mais (risos). Aí o homem, as controvérsias, são muito e muito, bom... (grifos nossos) (Padre Julião)

No trecho acima Padre Julião reafirma que a Igreja apreende a prevenção em sua

lógica: o não à camisinha é embasado em uma perspectiva que está inscrita no documento de fundação do catolicismo, a Bíblia - ou, como preferimos, na interpretação que o Vaticano confere à mesma. Numa outra linha, o que este e outros sacerdotes nos afirmaram é que apenas distribuir preservativo não adianta. A questão da AIDS, como acena Padre Julião, envolve múltiplas dimensões (econômicas, comunicacionais...), dentre elas, as morais - e, acrescentamos, sobre a qual a Igreja insiste que a sua perspectiva sobre o lugar do sexo na ordem do mundo prevaleça sobre outras perspectivas. Ainda assim, ele reconhece esta posição como, nas suas palavras: “paradoxal". Por que na construção de seu próprio argumento, o não à camisinha parece ser um obstáculo ao enfrentamento da epidemia - do ponto de vista biológico. Ao mesmo temo, quando se foca, apenas os aspectos eminentemente práticos de como caminha biologicamente o vírus, de um a outro ser, se desconsidera as dimensões "de salvação" do exercício da sexualidade, para ele, enquanto católico, questão fundamental. Ainda sobre o paradoxo apontado por Padre Julião, esclarece Frei Afrânio:

Certamente, aí é um ponto mais complexo, por que veja: a Igreja lida com o ideal, não é?! Então por exemplo, o ideal nosso é uma família perfeita, uma família equilibrada, ajustada... Perfeita eu não diria, mas diria assim uma família (...) que esta dialogando, uma família que... Onde existe fidelidade, a busca de serem fieis. Daí por que o casamento na Igreja é indissolúvel, "o que Deus uniu o homem não separe". A questão da sexualidade é... Realmente, nós temos repetido muito sobre a questão do homossexualismo, como uma realidade que ainda está em aberto, em discussão... O uso de preservativos, a igreja se contrapõe, né?! A Igreja não aceita, não é?! Porque, o grande problema, é como as campanhas são feitas e como o uso é estabelecido em metas governamentais. Então, é uma questão, ainda, bastante controvertida. E ainda está em aberto... Mas a igreja vai ter sempre uma posição que parece ser mais conservadora. Mas do que se trata? Ela lida com o ideal, né?! Nós queremos que os jovens cheguem a uma compreensão da sexualidade dentro da ótica e da perspectiva cristã, a ética cristã, daquilo que propõe o Evangelho de Jesus. (...) Que exigiriam uma vivencia da fé, uma compreensão da responsabilidade que nós temos, com Deus, com o dado da fé e com os outros, com o dado humano, com o social.

[E o que o senhor pensa sobre isso?] Olha, eu penso o seguinte, que, de um lado, eu estou de acordo com o que diz a nossa Igreja, né?! Por exemplo, eu acredito nas normas, eu acredito que as normas são importantes, são sérias. Agora, nós temos também que nos abrir, não é?! A questão que diz também a ciência, do que diz a realidade. A 
realidade é um dado fundamental para nós refazermos a nossa compreensão. Por exemplo, existe um ideal que se propõem, mas existe uma realidade que nós vivemos. Então, por exemplo, a Igreja(...) começa a abrir a possibilidade do uso de preservativos, sobretudo entre os casais, e assim por diante. Eu não sei bem, eu não tenho os dados oficiais, mas eu creio que é uma questão que a gente tem que levar em conta, não é?! E, lhe diria o seguinte: eu estou de acordo com as normas eclesiásticas, já que elas se referem à princípios éticos evangélicos; agora, certamente que estou disposto e gostaria também que a própria Igreja se abrisse sempre mais para o diálogo e para a realidade. Porque, veja: por um lado eu compreendo o que a Igreja tem a verdade da fé, mas eu estou em contato com pessoas, por exemplo, casais que não são fieis, e que a mulher pode se contaminar pela infidelidade do esposo, e aí?! O uso do preservativo, como é que fica? De fato, nós estamos sempre diante de realidades que nos interpelam, que nos questionam e que nos colocam diante de realidade. Não é?! Que infelizmente põem em risco também o ideal que nós temos, ou melhor, põem em cheque, né?! O ideal, quando a realidade é outra coisa. (Frei Afrânio)

É nesse contexto - que considera, no seu trabalho entre jovens de comunidades carentes e outros marginalizados, a realidade que desafia ideais - que Irmã Albertina, sem desprezar (do mesmo modo que Frei Afrânio) a lógica na qual a Igreja apreende a sexualidade, coloca:

Eu acho que é uma coisa... Você está vendo que a igreja não aprova camisinha de maneira alguma, né? Mas, eu, particularmente, eu acho que é uma coisa que tem que usar. Porque, se não usar... Já usando, já tem bastante pessoas contaminadas, imagine se não usar. Mas a igreja mesmo, acho que você vê ou escuta em jornais, que ela mesma não aprova, né? Então, eu particularmente, eu acho que as pessoas têm que usar. (Irmã Albertina)

Tomando esta diversidade de perspectivas relatadas pelos sacerdotes, afim de melhor compreender o quanto as prescrições da Igreja repercutem no cotidiano sexual dos católicos; e pensando o quão importante seria escutar os próprios fies, nos diferentes níveis de inserção na estrutura da Igreja, resolvemos enveredar por uma abordagem etnográfica mais clássica ${ }^{10}$. Como já aludimos, uma das pesquisadoras do projeto esteve de modo mais intensivo, e por um período mais prolongado de tempo, em uma comunidade onde a presença da Igreja Católica é de forte influência. Residindo na comunidade por dois meses, ela pôde escutar, e também observar, não apenas os sacerdotes, mas, e, sobretudo, as lideranças leigas envolvidas no cotidiano dos serviços religiosos, e também os fieis sem posição de liderança sobre temáticas relacionadas ao HIV/AIDS. No próximo tópico deste ensaio recuperamos um pouco do que foi esta convivência.

\footnotetext{
10 Também uma estratégia para lidarmos com a dificuldade de avançarmos no $\mathrm{N}$ de informantes católicos,
} quando nos fixávamos só nos sacerdotes. 


\section{OS CATÓLICOS E A MORAL SEXUAL DA IGREJA}

\section{A comunidade}

Nova Guanabara ${ }^{11}$ se caracteriza pela diversidade religiosa dos bairros populares da Região Metropolitana do Recife. Terreiros, centros espíritas, igrejas evangélicas das mais diferentes denominações, lugares conhecidos por pessoas que fazem "trabalho ${ }^{12}$ ", dentre outros, compõem o cenário religioso mais amplo do local pesquisado. É neste universo múltiplo da manifestação de fé que se localiza a igreja católica Imaculado Coração de Maria. Mesmo imersa num contexto diverso de outras religiões, esta paróquia busca imprimir suas marcas, no sentido de expandir sua doutrina para os fiéis, na vida cotidiana local.

Os líderes leigos católicos do bairro ressaltaram a participação da igreja na própria história do bairro. Lembraram das contribuições do primeiro padre na luta pela moradia dos chamados "invasores" da região praieira:

Houve essa invasão aqui, em 1957/58, que foi invasão mesmo. [...] cheguei do exército e já tava tudo cheio de mocambo, tudo invadido. Começou o seguinte, apareceu um bocado de políticos aqui doando lotes aqui, terrenos, E. Q., que já faleceu há muito tempo, N. C., aí eles construíram a noite os mocambos [...], a polícia vinha de manhã e derrubava, construíam a noite, a polícia derrubava. Eu to simplificando...

É desta forma que a história da igreja católica local confunde-se com a própria história do bairro. As conversas cotidianas com os membros dos grupos da igreja e com os demais católicos confirmam a importância da passagem de padre J. (o primeiro vigário) na solidariedade prestada à comunidade na construção dos barracos, chegando até ser preso enquanto mobilizava os moradores na conquista de um lugar definitivo para morar:

(...) tudo que tem aqui hoje foi através de muita luta e sempre a igreja católica sempre a frente, sempre a frente. Não pra comandar, a frente assim, na colaboração, no apoio. (...) A comunidade lutou muito por isso, a comunidade conseguiu muita coisa. $\mathrm{Na}$ época da ditadura, o padre J. foi preso, [...] P. E., que era vereador na época, hoje é deputado estadual, M. G., que era presidente do conselho na época. Aí tavam ajudando, coordenando, aí levaram eles presos. Aí a polícia achou que eles tavam contra o governo e prenderam eles. (Sr.Diomedes).

Se o primeiro padre fez parte da luta pela permanência dos moradores na época da fundação do bairro, os mesmos também contribuíram para a construção de um espaço para a congregação se reunir. Sr. Natanael, coordenador do Terço dos homens, informa que igreja católica tem quase a mesma idade de sua comunidade. A coordenadora do Apostolado da Oração ressalta que muitas pessoas que carregaram

Nome fictício.

Referência pessoas que ofertam serviços mágico-religiosos - os macumbeiros ou catimbozeiros. 
pedras para construir a gruta, que deu início ao que seria a igreja, ainda estão vivas para contar como tudo se deu.

Quando começou as missões era uma gruta. Isso aqui não tinha nada não, isso aqui, tudinho, era mato, areia de praia e tudo. Tinha a grutazinha, aí depois da gruta foi quando teve as missões aí fizeram a igreja do lado. [...] então resolveu fazer uma capelinha, e a gente mesmo carregava as pedras pra fazer aquela gruta, nós mesmos carregamos e subimos a gruta. (Natalia).

Atualmente a igreja é organizada por aproximadamente 12 grupos. Líderes

leigos católicos assumem a responsabilidade de coordenar diversas das atividades da igreja, dentre eles podemos destacar: Apostolado da Oração, as voluntárias, os vicentinos, o coral, catequese, crisma, perseverança, Terço dos homens, liturgia, Mãe Rainha, etc. Niedja relatou as funções que alguns desses grupos acima mensionados:

(A atividade) é feita pelos grupos. Dia das mães: quem tiver escalado naquele dia da missa é que toma conta do grupo. Aí tem a catequese que é das crianças, toma conta do mês de outubro, então é aquele grupo que toma conta. Pronto, hoje mesmo a gente vai ter reunião, hoje a noite, pra preparar a liturgia da semana santa. Aí vai cada representante de grupo, vai pra lá, pra organizar a procissão, essas coisas. (Niedja, responsável pela Mãe Rainha).

Algumas das atividades são sazonais e obedecem um calendário religioso anual.

Outras são mais rotineiras, como as preparações das missas. Estas compreendem nas escolhas dos cânticos, das leituras, podendo ser antecedida de terços em caso do mês de maio (mês mariano), ou do mês de abril (Semana Santa). Assim, mesmo as missas apresentam uma programação nuançada em conformidade com as datas consideradas importantes ao catolicismo.

No caso das atividades propriamente "extra-ordinária" há a preparação das procissões que abrange a confecção do andor que será levado pelos fiéis durante a caminhada, a escolha das ladainhas que obedecem a uma determinada ordem, a confecção de bandeiras com imagens do santo homenageado, e também compreende a preocupação dos membros da igreja em vestir os catequizandos de anjos para enfeitar ainda mais as festas católicas.

Como a nossa estadia na comunidade coincidiu com as festividades do mês de maio, compartilhamos das preparações iniciais do andor que homenageava Maria ${ }^{13}$. Observamos minuciosamente a forma como o andor é enfeitado. Este trabalho é realizado pelas mulheres do bairro, especificamente, aquelas ligadas à igreja, seja porque coordena algum grupo, seja porque é simplesmente católica e gosta de contribuir com o andamento das atividades religiosas.

13 Também ajudamos na confecção de faixas a serem expostas no dia da procissão e na confecção de bandeiras. 
Enquanto as mulheres se responsabilizam pela decoração do andor, os homens levam a imagem da santa durante a procissão. Esta caminhada religiosa é acompanhada de cânticos, de rezas e de fé. Mesmo aquelas pessoas que não acompanham a procissão, participam deste ritual religioso quando o mesmo vai passando nas proximidades de suas casas. Ela percorre algumas ruas dos bairros, segue depois para a igreja e em seguida a missa é realizada.

Além das procissões que homenageiam Coração Imaculado de Maria e também o Coração Imaculado de Jesus, ocorre ainda a procissão no mar no dia de São Pedro. Por se tratar de um lugar onde reside grande número de pescadores, a Colônia de Pescadores juntamente com a igreja local se empenham em homenagear o Santo o qual têm como patrono, no dia 29 de junho.

Como vemos a igreja exerce muita influência na dinâmica social dos moradores. Da igreja e ruas, rumando para a residência dos fies, destaca-se a forma como tenta difundir suas crenças por meio da prática de circulação da Mãe Rainha nas casas das pessoas $^{14}$. A coordenadora da Mãe Rainha e as missionárias mensalmente listam e ordenam os domicílios por onde a imagem da santa irá peregrinar. Convém destacar que a santa visita cerca de 240 famílias ao mês. As ministras exercem a função de levar a imagem de Mãe Rainha nas famílias, cada uma se responsabilizando por 30 famílias. Por fim, as famílias inscritas na lista recebem a visita da Mãe Rainha em seu lar durante o período de 24 hs no mês e se compromete em rezar o terço para a santa.

Além disso, a igreja tem um grupo chamado "as voluntárias" que é encarregado de rezar o terço no lar daquelas pessoas que não têm condições de se locomover até a igreja. Nessa visita fazem orações, lêem a bíblia, rezam terços e, se necessário, levam também a comunhão aos doentes. Outro grupo que exerce muita influência na comunidade é o Terço dos Homens. Conforme Sr. Natanael, que o coordena, há aproximadamente 800 grupos a nível norte-nordeste e cerca de cem mil homens rezando o terço. No contexto da paróquia de seu bairro, os terços são realizadas nas quartasfeiras do mês, com a freqüência de 60 a 65 homens por encontro. O objetivo do grupo é "resgatar o homem em termos de oração para a igreja, o homem é muito afastado da igreja e isso contribui muito pra que ele no seio da família [...] porque a religião católica principalmente em termos de oração era mais voltado para a mulher, ainda ê" (Natanael, coordenador do Terço dos Homens).

14 Fotografia de "Nossa Senhora" afixada em uma espécie de nicho de madeira. O artefato tem cerca de quarenta centímetros de altura e vinte e cinco centímetros de largura. 
Depois de contextualizar o trabalho desenvolvido pela Igreja no interior de Nova Guanabara, na perspectiva de consolidar fé e valores, convém agora nos debruçarmos na lógica das práticas conjugais cotidianas na interface com os princípios católicos sobre o matrimônio.

\section{Casamento, para sempre?}

Além dos já citados mecanismos de fortalecimento da fé e das crenças (procissões e festas dos santos, peregrinações da Mãe Rainha, rezas do terço, por exemplos) a Igreja busca transmitir seus ideais cristãos através das missas, como também, a partir do grupo Encontro de Casais com Cristo. Neste encontro, são feitas reuniões e discussões acerca de um tópico específico relacionado ao casamento e à família, a luz dos preceitos religiosos (cf. Machado, 1996). Somente homens e mulheres casados na Igreja podem coordenar o Encontro de Casais. O casal responsável pelo Encontro parece se configurar num modelo conjugal a ser seguido e alcançado pelos encontristas. Ao conversar com Maria Antônia, responsável por este grupo, identifiquei que dentre os princípios reforçados nos encontros com os casais, destacam-se o valor atribuído à monogamia e à fidelidade na manutenção da família.

A visão católica acerca do matrimônio reside primordialmente na expressão "até que a morte os separe", ou na assertiva "o que Deus une o homem não separa". Subsiste, nesta doutrina cristã, o entendimento de casamento pautado na crença de que o mesmo é indissolúvel.

Tais valores são tão fundamentais para o catolicismo que o não cumprimento dos mesmos pode implicar em restrições para homens e mulheres no seio da paróquia. Sublinhamos então, o depoimento de Paulina, coordenadora do Apostolado da Oração, no momento em que ela enuncia: "no meu curso apostolado da oração só entra mulheres casadas na Igreja. [...] mulheres só casadas no civil não podem pelo estatuto da Igreja [...] e só pode comungar, ou casada na Igreja ou viúvas". De outra vez, esta paroquiana relata que uma de suas amigas deseja muito participar do Apostolado, mas, seu desejo não pode ser concretizado porque seu marido se recusa a casar na Igreja.

No relato de Natália identificamos novamente limites impostos às pessoas que desrespeitam tais preceitos católicos. Se uma pessoa casada na igreja se separar do/a companheiro/a, ela pode participar das celebrações religiosas, no entanto, é impedido/a de receber o sacramento da comunhão. Acrescenta: “o sacramento, só pode receber, quem obedece às leis do mandamento". 
Mesmo tentando seguir à risca os princípios católicos, muitos paroquianos se deparam com realidades conjugais que não estão em conformidade com o exigido. Separações conjugais, re-casamentos, relações extraconjugais tanto por parte feminina quanto masculina surgem na vida cotidiana das pessoas do bairro. "Amigado" era o termo usado para se referir às pessoas que não eram casadas na Igreja e/ou no civil. Convém salientar que encontramos poucas uniões conjugais com vínculo civil e/ou religioso, como era os casos referentes aos membros lideres leigos católicos entrevistados.

Apesar de estabelecer distinção entre casado e amigado, a opinião das pessoas, não ligadas à igreja enquanto lideranças, converge na compreensão de que o casamento se baseia numa convivência harmoniosa. Madalena, católica, casada informalmente com o terceiro marido, assinala que: “casado, é o aquele que bem vive!”. É importante ressaltar que expressões da mesma natureza são comuns nas conversas habituais (sobre os casados não casados e o catolicismo cf. Quinteiro, 1996 e Porreca, 2004).

Ao seu turno, os lideres leigos católicos atribuem, sim, importância ao matrimônio e ao "papel" - ainda que não desconsiderem como fundamental a convivência harmoniosa no casal. Não obstante, uma mulher, que faz parte do grupo da igreja, contou-me das "escapadinhas" do marido e da dificuldade que tem de lidar com a situação. Ela refere preferir continuar no relacionamento e cumprir o mandamento da Igreja "até que a morte os separe". Até porque, diz ela, apesar dos aspectos negativos da traição, esta não se configura, na sua visão, numa justificativa para romper o laço marital. Ao invés disso, ressalta a satisfação de ver ainda casais comemorarem as bodas de ouro ou de prata e prefere continuar com o marido e a desempenhar seu papel de esposa fiel, e um dia voltar à Igreja para reafirmar nas bodas os laços de "fidelidade".

O fato é que a diversidade de arranjos conjugais e de parcerias sexuais no bairro é realmente plural, integrando além dos casados no papel e amigados, por exemplo, arranjos formados por uma mulher e dois maridos (co-habitando ou não todos em uma mesma casa), amantes (homem e mulheres) morando sozinhos ou com filho que recebem rotineiramente a visita dos parceiros (que contribuem ou não para a manutenção das casas, e podem ser ou não casados); homens e mulheres casados ou amigados que são traídos/as pelos/as companheira/os com outros homens e/ou mulheres (que podem ou não ter consciência da traição); etc (cf. Aquino, 2008). É neste universo alternativo de parcerias sexuais; conjugalidades e de famílias que pretendemos nos debruçar para entender os impasses da doutrina católica no cotidiano da comunidade. 


\section{A "gaia" de Cibele}

Vale destacar que as práticas alternativas de/nas conjugalidades, que estamos mencionando, não se referem apenas a comunidade dos "simples fies" católicos (e também os não-católicos) do bairro, diz respeito, também, aos contextos conjugais de alguns líderes leigos católicos ${ }^{15}$. Assim, depois de especular muito sobre esse assunto, perguntamos a um dos lideres leigos se, em algum momento, já tinha traído sua esposa. Este confessou, sem grandes dificuldades, que a traiu algumas vezes, justificando suas atitudes na prerrogativa de ser homem. ${ }^{16}$ Inclusive alguns desses "pulinhos", termo usado pelo informante para se referir à traição, ocorreram com mulheres que também fazem parte de grupos da igreja.

$\mathrm{Na}$ vida social dos moradores do bairro, os fatos relacionados às relações extraconjugais eram simplesmente publicizados pelo canal das fofocas ${ }^{17}$. Vizinhos, parentes, colegas comentavam sobre as "gaias ${ }^{18 "}$ que fulano ou beltrana estavam "levando" ou "botando". Em poucos minutos, as notícias alcançavam as conversas nas casas, nas calçadas, e até mesmo nas ruas.

Foi dessa forma que Cibele descobriu que seu marido estava lhe enganando com uma mulher que morava na vizinhança. Católica, 56 anos, casada na Igreja, conviveu durante muito tempo com a infidelidade do marido. Confessou que não se sentia feliz com ele: além de ser infiel, o mesmo também era "alcoólatra". Relata que o seu marido teve relação "a pulso" com ela. Diz que, após o ato não consentido, chorou a noite inteira.

Ao amanhecer, a primeira frase que disse ao marido foi: "você nunca mais chegue perto de mim!". “Eu não queria nem que ele me tocasse!”, acrescentou. Passou, então, a dormir com uma de suas filhas entre os dois, para evitar o contato com o marido. Hoje, diz ter tanta raiva dele que não lhe dirige uma palavra sequer. Atualmente, Cibele está separada do marido, mora com as filhas e os netos. Acha que o motivo principal da separação foi causado pela implicância constante dele com a filha dos dois. Certo dia, ele pediu que Cibele escolhesse entre ele e a filha. Ela optou pela

\footnotetext{
15 Vale destacar que pelo fato da integrante da equipe que residiu no bairro desenvolver uma dissertação que versa sobre o tema da Infidelidade Conjugal e Honra Masculina, ela buscou explorar com minúcias os casos pessoais e de terceiros relacionados a esta questão (Aquino, 2008).

16 Ressaltamos que a entrevista foi realizada individualmente, sendo que sua esposa chegou minutos finais da mesma, o que facilitou a coleta do dado. É importante destacar também, que perguntamos ao informante se sua esposa estava a par desse fato, em seguida, ele respondeu que achava que sua companheira desconfiava, mas não tinha certeza.

17 Sobre o debate referente às fofocas, consultar Elias e Scotson (2000), Fonseca (ano) e Aquino (2008).

18 Chifre - imagem que recobre o estigma de ter sido objeto de infidelidade.
} 
filha. É importante destacar que no contexto onde vive mãe é concebida como "a pessoa que tira tudo de si para dar aos filhos", reforçando o ideário do amor materno como incondicional e insubstituível. Neste caso, os laços consanguiíneos parecem prevalecer cobre os de conjugalidade. Assim, é ainda na inscrição que reforça a importância dos filhos na manutenção da família (leia-se, conjugalidade) que ela refere ter por muitos anos "agüentado" as "safadezas" do marido por causa daqueles.

Lembremos que, Cibele, ainda que se diga católica, não é membro de nenhum grupo da igreja. Na verdade, participar de forma mais intensiva das atividades da Igreja lhe é negado. Separada, ainda que por fatores "inteiramente" justificáveis ${ }^{19}$ e, de certa forma, alheios a sua própria participação na quebra do contrato matrimonial (ela se apresenta como esposa fiel e devotada aos filhos e ao marido), firmado junto à Deus e perante o Estado, pela condição atual encontra-se impedida, inclusive, de comungar.

A história desta mulher católica mostra-se como um valioso exemplo para discorrer sobre as correlações entre conjugalidade, infidelidade e AIDS. Predomina no imaginário social a idéia de que a esposa tem obrigações de manter relações sexuais com o marido, sendo esta uma de suas funções - como é possível notar na atitude do marido. Em adição, a tais idéias se junta a visão de que o uso do preservativo não deve fazer parte do "cardápio sexual" da pessoas casadas. O caldo de opressões então se engrossa, tornando Cibele mais vulnerável às de DST, e sobre a anuência e benção da Igreja. Ficamos nos perguntando como será que D. José Cardoso Sobrinho se posicionaria a respeito do caso de Cibele?

Se a Igreja não admite o uso da camisinha entre os casais, então como Cibele deveria agir conforme os princípios matrimoniais católicos? Como manter relação sexual com seu marido infiel, sem camisinha? Recusar simplesmente? Recusar como se numa ocasião ele manteve relações sexuais forçadas com a esposa? Até que ponto o marido também aceitaria o uso do preservativo?

Também cabe perguntar então, até que ponto ser fiel ao marido se configura realmente como uma forma eficaz de prevenção da AIDS ou de outras doenças? Quantas mulheres (e homens) convivem (muitas vezes sem saber) diariamente com as "puladas de cerca" do marido (esposa) e mantêm relações sexuais com o mesmo? Elas/eles devem deixar de usar preservativo para continuar obedecendo aos princípios da Igreja Católica e correr o risco de contrair doenças sexualmente transmissíveis?

19 Ao menos no nosso olhar - e no olhar jurídico do Estado laico à brasileira. 
Mais: e novamente pensando no caso específico de Cibele, mas que retrata o que acontece com inúmeras mulheres no cotidiano brasileiro, a violência doméstica, elas devem, e frente às muitas formas de agressões que lhes são impostas, manter o casamento a todo custo?

O relato de Frei Afrânio, transcrito no início deste trabalho, faz todo sentido, quando se precisa lidar com tantas espadas:

Porque, veja: por um lado eu compreendo o que a Igreja tem a verdade da fé, mas eu estou em contato com pessoas, por exemplo, casais que não são fieis, e que a mulher pode se contaminar pela infidelidade do esposo, e aí?! O uso do preservativo como é que fica? De fato nós estamos sempre diante de realidades que nos interpelam, que nos questionam e que nos colocam diante de realidade. Não é?! Que infelizmente põem em risco também o ideal que nós temos, ou melhor, põem em cheque, né?! O ideal, quando a realidade é outra coisa. (Frei Afrânio)

Não obstante a tensão entre a doutrina e a sua aplicação na casuística, acima apontada, não atinge apenas os sacerdotes. São objeto de reflexão (e uso) dos lideres leigos, que estão na ponta, conduzindo as diferentes atividades religiosas - além de suas próprias vidas. O depoimento de Antônia se revela extremamente significante neste contexto. A coordenadora do Encontro de Casais fica muito admirada com o fato do médico ainda solicitar que os casados precisam também usar camisinha. Nesse contexto, a confiança se afigura como um meio de prevenir qualquer doença sexualmente transmissível.

Se tem, na nossa religião, dentro da igreja, [...] sexo só com seu parceiro. [...] Se você é casada a vinte e dois anos, pra que você vai usar camisinha? [...] o povo julga e os médicos, as vezes, olha pelo lado dos outros clientes, que fazem as coisas erradas, de outra maneira, que vive traindo, [...] eles querem passar pra todo mundo usar. Quer dizer que você não garante! [...] ele é o único seu, e que ele é a única dele? você tem que ter confiança, né? [...] Você tem aquela pessoa, não precisa usar. (Maria Antônia, Encontro de Casais).

Assim, ao transmitir os preceitos religiosos, os líderes leigos católicos que foram entrevistados, manifestaram-se em relação ao assunto relações extraconjugais e AIDS. Enquanto uns concordavam com a visão da Igreja, outros divergiam de opinião. Para uma parte dos entrevistados, a fidelidade se constitui numa forma eficaz de evitar a AIDS e outras doenças. É por conta da fidelidade que as pessoas também podem respeitar outros valores cristãos, como a monogamia, o casamento e a própria família. Muitos argumentaram que a infidelidade desestrutura a família, visto que as práticas extraconjugais declaram o fim da mesma.

De modo divergente, outros informantes (às vezes os mesmos, em outros momentos da entrevista quando conseguiam refletir, sobre outros ângulos, sobre as 
questões que estavam sendo para eles colocadas) consideram o uso do preservativo como importante na prevenção da AIDS, haja vista a gravidade da epidemia e o contexto de vida sexual fora do casamento que reconhecem acontecer na comunidade onde vivem.

O que ela (a Igreja) diz é que é proibido. Que ela proibi que nossos fiéis católicos use a camisinha. Eu acho que isso é um pouco errado porque a AIDS esta aí, e ela (a Igreja) não trabalha em cima da prevenção. Ela da o conselho, nos seguimos. Mas a gente sabe o risco que é. Nesse ponto realmente eu não concordo, (...) Nesse ponto eu acho que a Igreja falha . (Natanael, coordenador do Terço dos homens)

Também Marta considera o uso da camisinha importante na prevenção de doenças, por esta razão, transmite uma educação sexual para as filhas orientando sobre o uso do preservativo. Entretanto, ela consegue coadunar em sua orientação a perspectiva católica de abstinência e postergação da sexualidade para o contexto do casamento, onde a fidelidade deve prevalecer na vida do casal. No seu relato a camisinha deve surgir como estratégia a ser usada se (e/ou quando) "a carne" for mais forte que o ideal proposto pelos evangelhos. Afinal, faz parte da condição humana o pecado.

Neste contexto de dissensos, chama atenção a recorrente referência de que a questão da prevenção AIDS não é, explicitamente, sequer tematizada ${ }^{20}$, ainda que pelo viés da abstinência, nos diferentes âmbitos e instâncias do catolicismo de Olinda e Recife.

E em relação ao trabalho da AIDS aqui na nossa paróquia, infelizmente não tem. Até um certo ponto eu critico. Não a Igreja, em si, mas alguns padres, que não tomam essa iniciativa de fazer um trabalho social, como é a preocupação com a AIDS. Aqui na nossa paróquia não tem, e não sei em outras. Mas também não sei também o clima... Mas, infelizmente, a AIDS é um problema sério, que afeta a todo povo. E ela não escolhe classe social. E a Igreja, que é contra a camisinha, deveria se engajar também com orientação aos fieis. E essa é uma falha grave, não é no caso a igreja aqui, acho que é a religião de um modo geral. (Natanael, coordenador do Terço dos homens)

\section{CONSIDERAÇÕES FINAIS}

Ainda que do ponto de vista estilístico seja desaconselhável apresentar idéias novas nas finais considerações de um texto, queremos quebrar o protocolo e apresentar fleches dos achados de uma importante pesquisa realizada pelas Católicas pelo Direito de Decidir $^{21}$ e o IBOPE (IBOPE/CDC-Br, 2007) ${ }^{22}$. De alguma forma ela expressa em

\footnotetext{
20 Lembremos que falar sobre os preceitos morais da Igreja em relação à sexualidade não necessariamente se desdobra em pensa-la na interface com as DST e a AIDS.

21 Sobre as Católicas pelo Direito de Decidir, cf. o site: http://catolicasonline.org.br/.

22 A pesquisa foi realizada entre novembro de 2006 e janeiro de 2007, onde foram ouvidas a opinião de jovens católicos, de ambos os sexos, de idade variando entre 18 e 29 anos, das cinco regiões do Brasil, sobre
} 
números muito do que ouvimos em conversas informais enquanto circulávamos no dia a dia de Nova Guanabara. Será a partir de tais achados que iniciaremos o fechamento deste ensaio - ou, em outra linha, que colocaremos as indagações que surgiram desta primeira análise descritiva dos dados que coletamos, abrindo discussões que, esperamos, mobilizem nossos pares para novas pesquisas e reflexões.

$\mathrm{Na}$ pesquisa IBOPE/CDC-Br (2007) figura que 79\% dos jovens entrevistados discordam que "as pessoas só devem ter relações sexuais após o casamento". Desagregando os dados por sexo, temos que $82 \%$ dos homens e $75 \%$ das mulheres discordaram de tal afirmação. Para o Nordeste o percentual de discordância, considerando ambos os sexos, ficou em 75\%. Já no que se refere ao "o uso da camisinha para evitar a gravidez e as doenças sexualmente transmissíveis", $96 \%$ dos entrevistados concordaram com a afirmação. Mesmo percentual quando se considera apenas a região Nordeste. Do total de entrevistados, $81 \%$ concordaram que "um jovem com menos de 18 anos tenha o direito de ter acesso à camisinha e outros métodos anticoncepcionais sem a autorização dos pais", no Nordeste $74 \%$. Finalmente, $88 \%$ (87\% dos nordestinos) concordaram que "uma pessoa pode usar métodos anticoncepcionais e continuar sendo uma boa católica". Em adição, $62 \%$ do entrevistados no Brasil (60\% no Nordeste) concordam que "a Igreja Católica, ao condenar o uso da camisinha, ou outros métodos anticoncepcionais e sexo antes do casamento assume uma posição atrasada" (IBOPE/CDC-Br, 2007).

Estes dados apontam para o fato de que ainda que a opinião formal da Igreja seja a da abstinência e a postergação da vida sexual pós-casamento como a única forma aceitável de se prevenir das DST e evitar a Gravidez na adolescência, os católicos e católicas jovens, entrevistados na pesquisa IBOPE/CDC-Br (2007), não parecem incorporar a opinião daquela como suas próprias opiniões. No que se refere à visão de sexualidade, a pesquisa revela que para os jovens católicos os dogmas da Igreja parecem não servir mais como os únicos princípios “de e para” (Geertz, 1978) orientar as condutas.

Mas, cremos, não devemos nos apressar e "jogar a criança junto com a água do banho". É importante pensar no outro lado da moeda, nos $38 \%$ de jovens católicos que não concordam que a posição da Igreja é atrasada; também nos $4 \%$ que não concordam com o uso do preservativo. Em outras palavras, os dissensos precisam ser considerados.

sexualidade e reprodução, na interface com as posições formais da igreja católica sobre tais questões, em especial sobre os usos dos métodos contraceptivos e de prevenção às DST. 
Os sentidos das palavras e das coisas, difíceis de serem alcançados em pesquisas de opinião, como a realizada pelo IBOPE/CDC-Br (2007), precisam ser mais bem investigados.

A título de exemplo, poderíamos mais uma vez chamar os nossos interlocutores do Recife para iluminar a leitura dos dados trazidos pelo IBOPE/CDC-Br (2007). Recorrentemente, sacerdotes, leigos e fiéis nos disseram que a posição da Igreja tem um sentido, uma lógica, e concordam com ela (os 38\% da pesquisa, acima mencionados), mas que, frente à realidade sexual brasileira, não se deve descartar a camisinha como forma de prevenção. Nessa linha, levantamos como hipótese que 34\% dos entrevistados na pesquisa IBOPE/CDR-Br (2007) (38\% dos que concordam com a posição da Igreja, menos os $4 \%$ dos que não concordam como o uso do preservativo - inteiramente afinados com tal posição), caso fosse feito um cruzamento entre estas duas questões (concordar com o uso do preservativo e, ainda assim, concordar com a opinião da Igreja), expressariam esta dupla de opiniões - aparentemente uma ambigüidade. Não obstante, se num primeiro olhar dúbio, se posicionar desse modo frente às duas opiniões ofertadas, no nosso entender, é bastante coerente, quando pensamos que nem sempre as crenças conduzem às ações idealmente esperadas. Nessa perspectiva, o que nossos entrevistados argumentam é que frente à gravidade da epidemia, as duas perspectivas camisinha e fidelidade/abstinência - devem figurar como possibilidades as quais as pessoas poderiam recorrer.

O que não se pode inferir dos dados da pesquisa acima apresentada é que os ideais de fidelidade e postergação da iniciação sexual para o casamento, deixaram de figurar entre os jovens entrevistados. Eles não foram chamados a falar sobre si mesmos, mas sobre um ente genérico a "pessoa". Mereceria um maior aprofundamento a questão do modo como os católicos articulam, em suas próprias trajetórias de vida, os vários referenciais socialmente disponíveis.

Até porque, é importante lembrar, o Brasil é uma sociedade complexa e não devemos esperar que os adeptos católicos se digam e se façam, exclusivamente, a partir da religião em que se batizaram e/ou dizem praticar. Não obstante, também não podemos desconsiderar a importância da religião no processo de subjetivação. Ora, e se quisermos ser coerentes com a abordagem que orienta nosso olhar, a da construção social da sexualidade (cf. Vance, 1989, Gagnon, 2006), não podemos negar o ideário católico sobre sexualidade como importante referência para a subjetivação sexual destes. 
Nessa linha, quando da construção de tecnologias de intervenção devemos atentar, sim, para a perspectiva do catolicismo, relacionada à sua moral sexual, no momento de pensar em estratégias específicas para seus adeptos. O que não se pode pedir é que campanhas populacionais sobre HIV/AIDS, em um Estado laico como o brasileiro, privilegiem uma perspectiva moral em detrimento de outras; ou, mais: que se estigmatize categorias populacionais por não se comportarem de acordo com uma moral sexual específica - como quer D. José e o Vaticano.

Indo adiante, a questão que fica, para nós - preocupados com questões de saúde pública - e para Igreja - que imaginamos, deve se preocupar com a saúde de seus seguidores - é de como conduzir estratégias de promoção à saúde que dêem conta do contexto plural religioso brasileiro, que atravessa famílias e casais, e, em adição, numa sociedade marcada por estruturações opressoras de gênero, raça, classe, orientação sexual etc. Vertentes que, na sinergia em que operam, muitas das vezes comprometem a autonomia dos sujeitos, vulnerabilizando-os a diversos agravos - como no caso de Cibele, objeto de nossa análise. Estas questões não podem ser simplesmente jogada para "baixo do tapete" afim de que um ideal, supostamente a serviço da vida, prevaleça, ainda que as custas de muitas mortes.

Neste sentido, as palavras do saudoso Dom Helder Câmara, Arcebispo Emérito de Olinda e Recife, ainda são bastante pertinentes no contexto do enfrentamento à epidemia do HIV/AIDS pela Igreja e pelo Estado:

"Ultrapassa-te a ti mesmo a cada dia, a cada instante...

Não por vaidade, mas para corresponder à obrigação sagrada de contribuir sempre mais e sempre melhor, para a construção do Mundo..."

Dom Helder Câmara

\section{REFERÊNCIAS}

ARIÈS, P., 1987. São Paulo e a carne. In: ARIÈS, P. e BÉJIN, A. (Orgs.) Sexualidades ocidentais. São Paulo: Editora Brasiliense.

AQUINO, F. 2008. Homens "cornos" e mulheres "gaieiras": infidelidade conjugal, honra, humor e fofoca num bairro popular de Recife-PE. Dissertação (Mestrado em Antropologia) - Universidade Federal de Pernambuco.

ELIAS, N \& SCOTSON, J., 2000. Os estabelecidos e os outsiders. Rio de Janeiro: Jorge Zahar Editor. 
ENRIQUEZ, E. 2001. O papel do sujeito humano na dinâmica social. IN: MACHADO, M.N.M. et. al (org.) Psicossociologia - análise social e intervenção. B.H. Autêntica.

FONSECA, C. L. W. , 2000. Família, fofoca e honra: etnografia de relações de gênero e violência em grupos populares. Porto Alegre: Editora da UFRGS.

FOUCAULT, M., 1993. História da sexualidade I: a vontade de saber. Rio de Janeiro: Graal.

FREIRE, P., 1989. Pedagogia do oprimido. Rio de Janeiro: Paz e Terra

GAGNON, J., 2006. Uma Interpretação do Desejo.Rio de Janeiro, Garamond.

GEERTZ, C., 1987. A interpretação das culturas. Rio de Janeiro: Guanabara.

IBOPE/CDC-BR. 2007. Pesquisa de opinião pública sobre temas ligados ao comportamento das pessoas e a posição da igreja católica. Disponível em: <http://www.ibope.com.br/opiniao_publica/downloads/opp008_cdd_mai07.pdf.> Acesso em 09 de julho de 2007.

MACHADO, M. D., 1996. Carismáticos e pentecostais: adesão religiosa na espera familiar. São Paulo: Editora Autores Associados e ANPOCS.

PAIVA, V., 2002. Sem mágicas soluções: A prevenção e o cuidado em HIV/AIDS e o processo de emancipação psicossocial. Botucatu: Interface, v. 6, n. 11, p. 25-38.

PARKER, R. G. , 2003. Building the Foundations for the Response to HIV/AIDS in Brazil: The Development of HIV/AIDS Policy. Divulgação em Saúde Para Debate, v. 27, p. 143-183.

PARKER, R. G. ; BERKMAN, A. ; GARCIA, J. ; MUNOZ-LABOY, M. ; PAIVA, V. , 2005. A Critical Analysis of the Brazilian Response to HIV/AIDS: Lessons Learned for Controlling and Mitigating the Epidemic in Developing Counties. American Journal of Public Health, v. 95, n. 7, p. 1162-1172.

PORRECA, W., 2004. Famílias recompostas: casais católicos em segunda união. Dissertação (Mestrado em Psicologia). Faculdade de Filosofia, Ciências e Letras de Ribeirão Preto/USP. Ribeirão Preto (SP)

QUINTEIRO, M. C., 1987. Casados não casados: uniões consensuais nas camadas médias e populares. Dissertação (Mestrado em Antropologia Social) Universidade de São Paulo. Faculdade de filosofia letras e ciências humanas. São Paulo (SP)

SEFFNER, F.; DA SILVA, C.; MAKSUD, Í.; GARCIA, J.; RIOS, L. F.; NATIVIDADE, M.; BORGES, P.; PARKER, R.; TERTO JR., V., no prelo. Respostas religiosas à AIDS no Brasil: impressões de pesquisa acerca da Pastoral de 
DST/Aids da Igreja Católica. In: Ciencias Sociales y Religión/Ciências Sociais e Religião, n 10.

VANCE, C., 1989. Social Construction Theory: Problems in the History of Sexuality. In: ALTMAN, D. et alii. (ed.) Homosexuality, Which Homosexuality? Londres: Gay Men's. 